\title{
Use of waste in production of thermal insulating slabs
}

\author{
Ilya Morozov ${ }^{1}$, Anna Loktionova $^{1}$, Nadezhda Galtseva, ${ }^{1, *}$ and Vasily Korovyakov ${ }^{2}$ \\ ${ }^{1}$ Moscow State University of Civil Engineering, Yaroslavskoe shosse, 26, Moscow, 129337, Russia \\ ${ }^{2}$ Research Institute Mosstroy, 105066, Moscow, Russia
}

\begin{abstract}
The purpose of the article is to find the rational use of waste formed in the course of production of heat-insulating plates on the basis of foamed polyisocyanurate, together with gypsum binder. Some tests were carried out to determine the thermal conductivity and strength of the obtained material, the estimation of their characteristics, the analysis of efficiency and needs of the final product in the market of building materials is given. It was established that when gypsum binder and additives are used together the result is a material with the best initial indicators of heat insulation and strength. The results of research showed that at the optimum composition of the gypsum and additives the material is not inferior to the individual indicators of drywall and gypsum. Board which proves both its efficiency and its need for construction.
\end{abstract}

\section{Introduction}

Nowadays the most part of enterprises relevant to the construction industry in the production of a particular product are faced with the problem of the problem of excessive waste generation. Waste is used materials that do not have the original qualities [1]. As a rule they are subjected to subsequent disposal or reuse. It is worth paying attention the first option is resorted to much more often because secondary use involves research as well as testing which takes a long time sometimes. A common method of utilization of wastes is the disposal of waste which does not always have a positive effect on environment [2]. Taking modern realities into account the main task is maximum reuse of materials wherever it's possible.

The Russian Federation is directly interested in efficient use of waste in the production of building materials. RF Government decree of 25 January 2018 № 84 reflects the problems of waste management, development of the industry for processing, disposal of waste for the moment. Ecological safety directly dependent on the possibility of minimum amount of waste disposal and resource saving is an actual direction. Transformation of waste for production into secondary raw materials remains an unsolved task at the Federal and regional level. The Federal state statistics service gives the data (Fig.1). In 2005, in the Russian Federation it was recorded the formation of about 3035,5 million tons of waste but

* Corresponding author: GalcevaNA@mgsu.ru 
in 2015 it was recorded 5060 million tons of waste that is the figure increased by 68 percent for 10 years. The growth rate is enormous.

During the research work a number of questions were raised. Is it possible to find an effective use of waste in the production of thermal insulation boards based on foamed polyisocyanurate and in such a way as not to harm the environment? What is the probability of using such material in the construction of buildings and structures? Is there a market need?

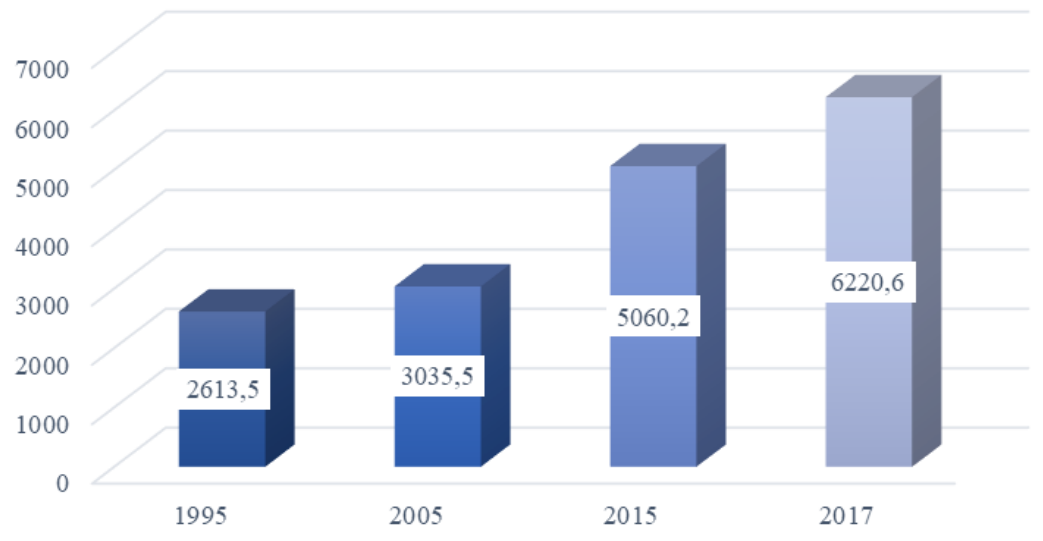

Fig.1. Statistics on waste generation.

\section{Materials and methods}

According to the information provided on the official website of «TechnoNIKOL», PIRbased materials have the best water absorption performance (not more than $1 \%$ ), Flammability (G1, G2), thermal conductivity of existing insulation $(0.021 \mathrm{~W} / \mathrm{m} * \mathrm{~K})$, and they are not subject to rot and resistant to mold, fungus. Plate insulation TechnoNIKOL is a thermal insulation material of a new generation based on foamed polyisocyanurate. PIR has a unique cell structure, both sides are coated with a special foil (Fig.2). Pay attention to the characteristics of the material (Table 1) [3-5].

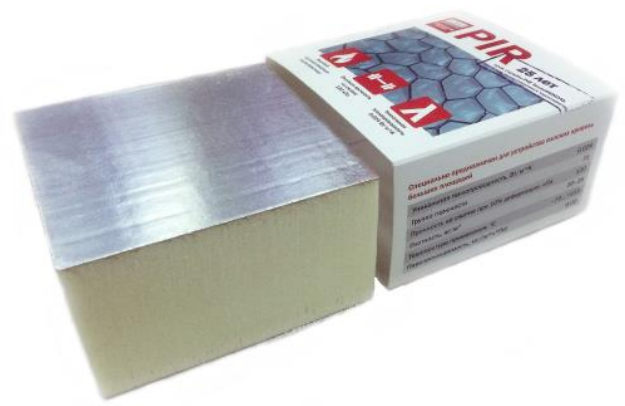

Fig. 2. Illustration of thermal insulating slabs. 
Table 1.Material characteristics.

\begin{tabular}{|c|l|c|}
\hline No & \multicolumn{1}{|c|}{ Name } & Indicators \\
\hline 1 & Thermal conductivity, $\mathrm{W} / \mathrm{m} * \mathrm{~K}$ & 0,024 \\
\hline 2 & Flammability group & $\Gamma 1$ \\
\hline 3 & Compressive strength at $10 \%$ deformation, $\mathrm{KPa}^{\circ}$ & 120 \\
\hline 4 & Application temperature, ${ }^{\circ} \mathrm{C}$ & $-70 \ldots+110$ \\
\hline 5 & Vapour permeability, $\mathrm{mg} /(\mathrm{m} * \mathrm{~h} * \mathrm{PA})$ & 0,05 \\
\hline
\end{tabular}

Gypsum is widely used in the field of construction. Gypsum binder is not inferior to cement in application but fuel, which is spent on its production, is spent many times less [67]. The scope of application is determined by the following characteristics: high level of fire resistance due to the cost of a large amount of heat for evaporation of crystallization water and the formation of the porous structure of gypsum having a high coefficient of thermal resistance as well as hygiene and low density [8].

The characteristics of each material individually explain their widespread use but their joint work is interesting. In the process of research, the optimal composition for the production of materials based on PIR was determined, which has the following values (Table 2).

Table 2. Optimal composition.

\begin{tabular}{|c|l|c|}
\hline No & \multicolumn{1}{|c|}{ Name } & Percentage (gypsum: additives) \\
\hline 1 & $\begin{array}{l}\text { Sample with addition of 5\% fine fraction 2- } \\
5 \text { mm, taken in an amount of 1.5\% }\end{array}$ & $98,5: 1,5$ \\
\hline 2 & $\begin{array}{l}\text { Sample with addition of coarse fraction, in } \\
\text { the amount of 1\% }\end{array}$ & $99: 1$ \\
\hline 3 & $\begin{array}{l}\text { Sample with pressed additive, in the } \\
\text { amount of 5\% }\end{array}$ & $95: 5$ \\
\hline 4 & $\begin{array}{l}\text { Sample with pressed additive, in the } \\
\text { amount of 10\% }\end{array}$ & $90: 10$ \\
\hline
\end{tabular}

During the semi-annual observation of the beam samples, the dimension of which is 40x40x160 mm, and boards having a size of 100x100x20 mm, a tendency was identified: the samples containing additives showed greater strength under mechanical stress than the samples of pure gypsum. Based on this, as well as taking into account the brand of gypsum, an approximate graph of strength versus time was drawn up (Fig.3).

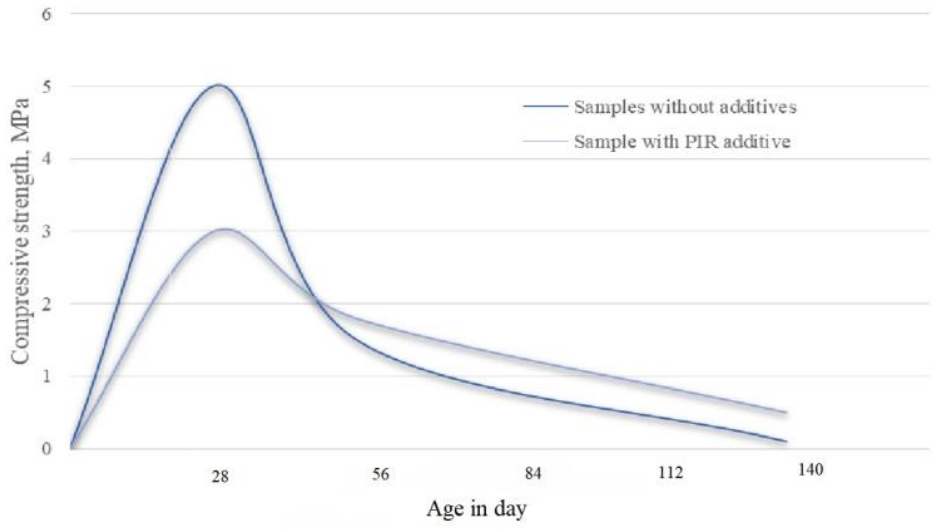

Fig. 3. Graph of strength versus time. 
The use of PIR in gypsum binders reduces the strength of the composition by two points, in other words, using the brand G-5, ultimately get gypsum grade G-3. In the production of resistant gypsum products it is necessary to use a more expensive gypsum binder, the amount of its decrease in the initial composition due to the presence of additives.

In the course of bending tests, it was found that the results had the same values, with regard to strength, the value varies from 3-5 $\mathrm{MPa}$, which in turn gives the right to believe there is a percentage of error in the performance of manual work, in the industrial field, the numerical indicators will be more accurate and higher.

Thermal conductivity is one of the main characteristics of the material. The indicator is fundamental, which is explained by the climatic conditions in the territory of the Russian Federation. [9-10].

After testing to determine the thermal conductivity, a diagram of numerical indicators was made (Fig. 4). The result was that PIR-based products have similar but lagging values compared to drywall. The analysis in the course of which it was found out that the pressed additive PIR in the basis of the gypsum product has positive properties was performed in a visual way on the diagram: strength, as a reinforcing frame; porosity; water repellency; insulation. Based on this, this work will be continued to determine the best composition, as well as high thermal, acoustic, mechanical and physical properties.

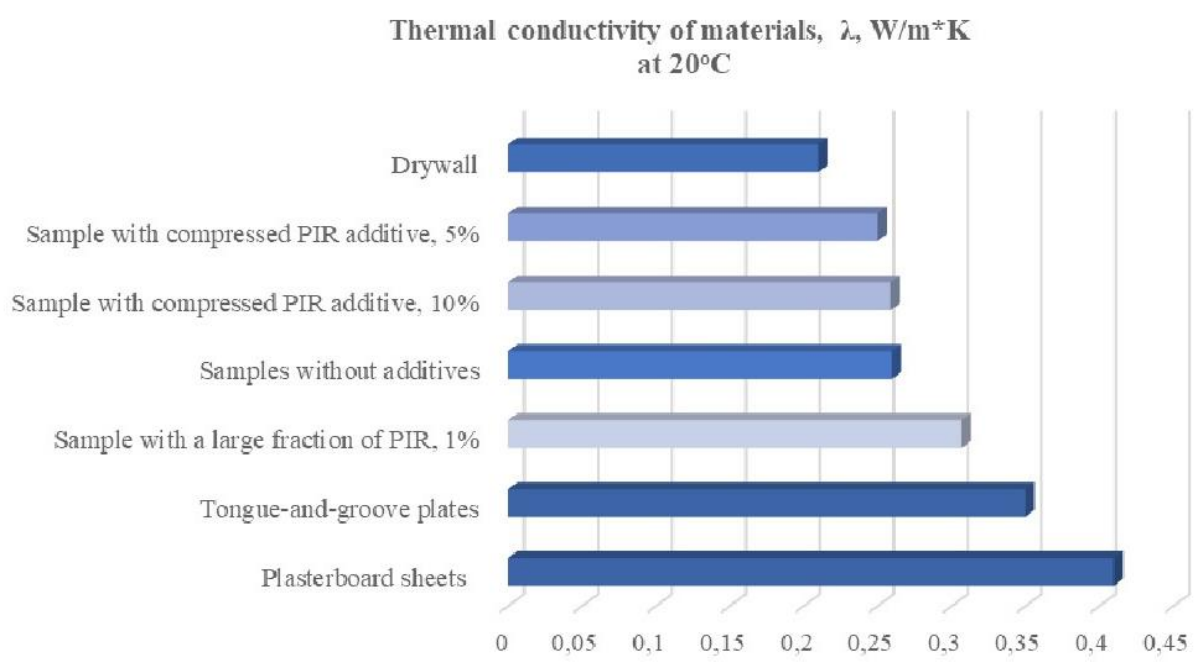

Fig. 4. Diagram of digital indicators. 
Samples subjected to the test has dimension 100x100x20 mm (Fig.5).

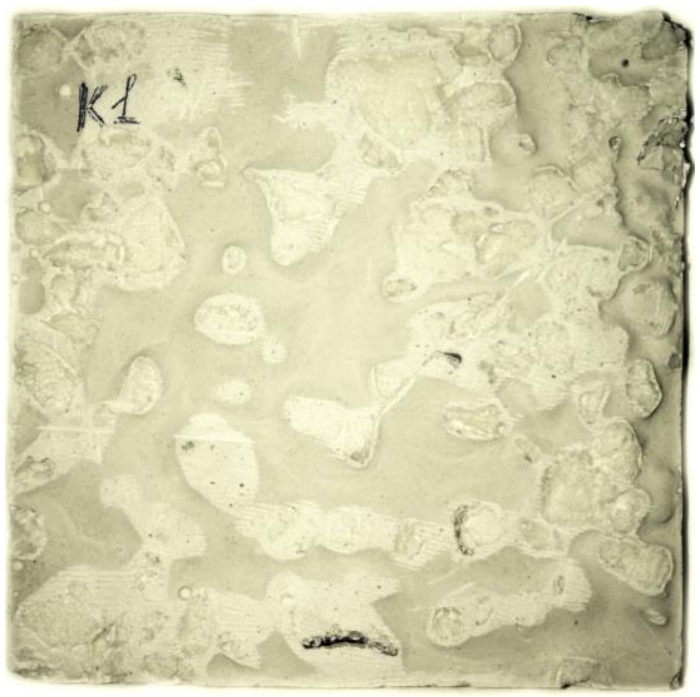

Fig. 5. Gypsum material with additive.

The use of the above-mentioned production waste can reduce the amount of gypsum binder used, which leads to a reduction in cash costs in the process of manufacturing the material. In the nearest future, such products can become competitors to gypsum panels and walls, drywall, up to partial or complete replacement [11]. Constructions with the use of waste products in the manufacture of thermal insulation boards based on PIR have greater thermal insulation and sound insulation, thus having an undeniable advantage.

\section{Results and discussion}

In the process of creating products based on ground additive we have to deal with the problem that arises during the separation of the additive into fractions. Separation of small particles carrying danger to human health is observed, therefore, it is necessary to provide environmental measures to reduce air pollution by installing additional filters, as well as to carry out their timely maintenance in connection with their frequent clogging of the smallest fractions. Disposal of small fractions at the moment is not possible, a large fraction should be subject to crushing - this is an additional cost for the purchase of necessary equipment, an exception in this case is not the area of electricity. The drying time of PIRbased products is 2.5 times longer than that of a conventional gypsum product, which leads to a large amount of time for production. The dust particles in the pressed additive are part of the additive itself and do not cause the previously mentioned difficulty. Pressed additive in the production needs grinding, the thoroughness of which is not as important as most concrete products.

With the extruded additive the industrial features are completely different. This type of additive occupies a small spatial volume, and, therefore, storage space for it will need much less. The best results with the use of pressed additives confirm the feasibility of its use, because the release of dust particles leads to a deterioration of the environmental situation. The most well-known disadvantage of drywall is the susceptibility to destruction from 
moisture. Given that in the process of research samples using a large fraction had a long time to dry, it can be assumed that in conditions of high humidity the use of these materials is appropriate. In this case, it is a step to obtain a moisture-resistant gypsum material [1214].

The problems that have to be faced should not call into question the possibility of using waste in the production of thermal insulation slabs, because the income from the potential volume of sales of goods can justify the costs, for example, for the purchase of equipment [15].

\section{Conclusions}

Thus, the study of the effective use of waste in the production of thermal insulation slabs was a step towards solving the current and global problems- the possibility of re - use of material residues from production as secondary raw materials. It was found that the addition of small fractions of $2-5 \mathrm{~mm}$, as well as large ones in the form of waste from polyisocyanurate foam is a good filler, which increases the individual characteristics of the final product. The rationality of the use of the material in construction is proved, because the heat insulation indices are higher in comparison with drywall and gypsum boards. It is important that throughout the research work it was about the secondary use of the material, i.e. processing, requiring additional costs of electrical energy, is virtually absent. The created material may well become a competitor in the market of building materials. Research in this direction can and should be continued.

\section{References}

1. V.Bespalov, O. Gurova, O. Paramonova, N. Samarskaya, E. Lysova, N. Yudina, MAT. Web of Conf., 73 (2016) https://doi.org/10.1051/matecconf/20167303008

2. A.V. Aleksanin, S.B. Sborshchikov, Vest MGSU, 229-235 (2013)

3. N.V. Mostovaya, All. of Scien., 3, 3-6 (2018)

4. M.A. Burtzeva, E.A.Mednikova, All. of Scien., 122-125 (2017)

5. D.V. Kulsaitova, All. of Scien., 1, 32-35 (2018)

6. A.A. Palamarchuk, O.A. Shishakina, A.G. Arakelyan, MATH. AND TECH. SCIEN., 173-175 (2017)

7. M.S. Sofronova, ALITinf.: Cem. Conc. Dr. Mix, 86-95 (2013)

8. A.A. Semenov, ALITinf.: Cem. Conc. Dr. Mix, 67-73 (2009)

9. B.M. Rumyantsev, A.D. Zhukov, Roof. and insul. Mat., 11-13 (2013)

10. B.M. Rumyancev, A.D. Zhukov, E.Y. Bobrova, T.V. Smirnova, Indus. and civ. Build., 1, 32-36 (2015)

11. D.K. Timokhin, E.S. Golovnov, Tech. Regul. In trans. Constr., 49-51 (2017)

12. N.A.Galtseva, E.N Buldyzhova, A.F Burianov, Act. Probl. of mod. Sc., tech. and educ., 2, 195-197 (2013)

13. M. M. Chen, F. Q. Zhao, T. L. Fan, M. M. Zhang, S. J. Liu, H. J. Liu. A waterpr. and Imper. Stor. Gyp. block and its prep. Meth., CN 105924120A [P] (2016)

14. S.D. Kozlov, V.G. Bul. of Scien. and Pract., 135-138 (2017)

15. I.V. Stefanenko, Constr. and reconstr., 95-98 (2011) 